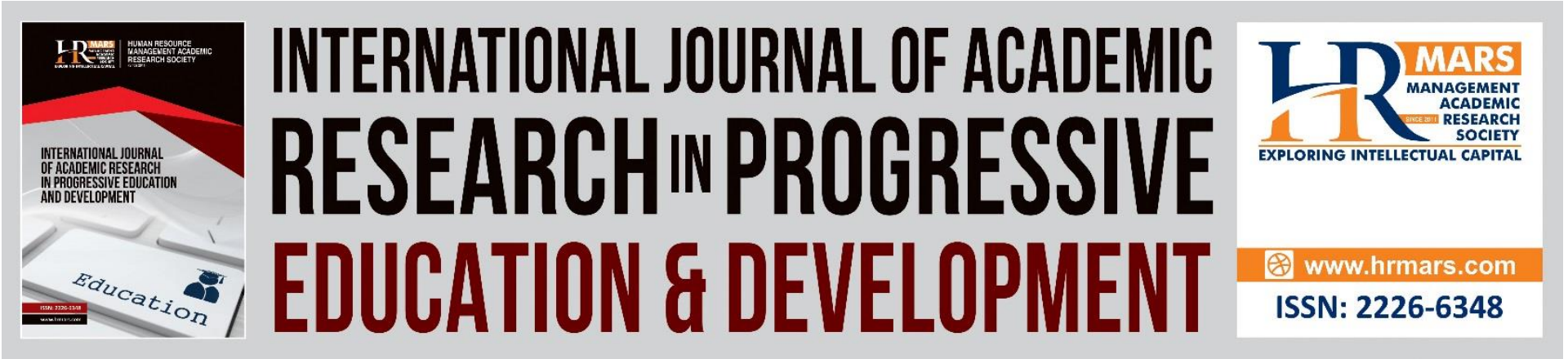

\title{
The Relationship between English Writing Ability Levels and EFL Learners' Metacognitive Behavior in the Writing Process
}

\section{Zu-Feng Wei, Hui-Fang Shang, Paul Briody}

To Link this Article: http://dx.doi.org/10.6007/IJARPED/v1-i4/12012

DOI: 10.6007/IJARPED/v1-i4/12012

Received: 18 September 2012, Revised: 24 October 2012, Accepted: 02 November 2012

Published Online: 27 November 2012

In-Text Citation: (Wei et al., 2012)

To Cite this Article: Wei, Z.-F., Shang, H.-F., \& Briody, P. (2012). The Relationship between English Writing Ability Levels and EFL Learners' Metacognitive Behavior in the Writing Process. International Journal of Academic Research in Progressive Education and Development, 1(4), 193-217.

Copyright: (c) 2012 The Author(s)

Published by Human Resource Management Academic Research Society (www.hrmars.com)

This article is published under the Creative Commons Attribution (CC BY 4.0) license. Anyone may reproduce, distribute, translate and create derivative works of this article (for both commercial and non-commercial purposes), subject to full attribution to the original publication and authors. The full terms of this license may be seen

at: http://creativecommons.org/licences/by/4.0/legalcode

Vol. 1(4) 2012, Pg. 193 - 217

Full Terms \& Conditions of access and use can be found at http://hrmars.com/index.php/pages/detail/publication-ethics 


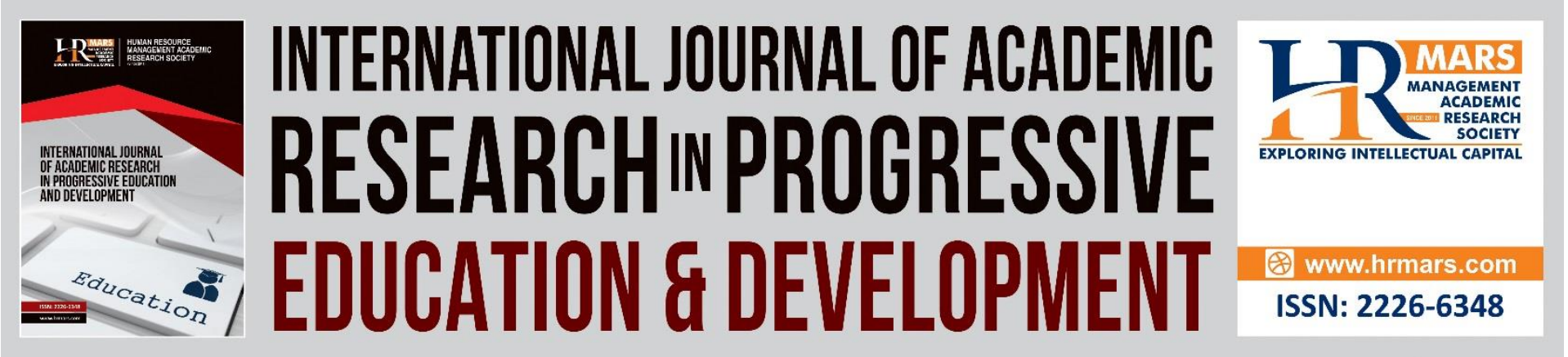

\title{
The Relationship between English Writing Ability Levels and EFL Learners' Metacognitive Behavior in the Writing Process
}

\author{
Zu-Feng Wei \\ Graduate Student, Department of Applied English, I-Shou University, Taiwan \\ Hui-Fang Shang \\ Professor, Department of Applied English, I-Shou University, Taiwan \\ Email: hshang@isu.edu.tw \\ Paul Briody \\ Lecturer, Department of Applied English, I-Shou University, Taiwan \\ Email: paulthebrain@hotmail.com
}

\begin{abstract}
The impact of globalization has been felt by those who need to communicate in English. The corollary to this is that an emphasis is now placed on traditional writing skills within an increasingly complex range of communicative media. To meet the demands of writing competence that EFL learner's now face, Flower and Hayes (1981) proposed a cognitive process writing model to provide insights, into how writers go about planning, generating, and revising, during the process of writing. Sitko (1998) proposes that one way to engage students in the cognitive process is to provide instruction in metacognition. Since there have been fewer studies focusing on examining the impact of metacognitive behavior in the Taiwanese learning context (e.g., You \& Joe, 2001, 2002), the purpose of this study is to investigate the relationship between English writing ability levels and EFL learners' metacognitive behavior during the writing process; and further, to explore their attitudes and perceptions, concerning metacognitve operations, during the writing process. Both quantitative and qualitative research methods were used in this non-experimental study. Subjects in the present study were 152 students majoring in Applied English at a university in the south of Taiwan. The finding of this study reveals that high-level writers make better use of metacognative behavior in the stages of planning as well as reviewing; however, there is no significant difference at the translating stage. The interview results show that highlyproficient writers: generate complete ideas, and concern themselves with the needs of their audience and the demands of specific genres, as well as additionally organizing an outline in English during the planning stage; whereas most intermediate- and low-proficient writers, only generate rough ideas and make an outline in Chinese. It is expected that the results of the present study will inform EFL writing teachers of the pedagogical implications and
\end{abstract}


conclusions to be drawn from a fuller understanding of the metacognitive writing behavior exhibited by proficient EFL students.

Keywords: Metacognitive Behaviors, Planning, Translating, Reviewing, EFL Writing Ability

\section{Introduction}

With the development of globalization has come the concomitant requirement for skilled writing practitioners. English writing is more than a feature of language acquisition; it is a prerequisite for effective communication, across a range of human activities. Possessing writing skills in such an environment is a mark of some distinction in itself, but it is also indicative of other attributes and propensities. The possession of good writing skills has oft been noted as a powerful predictor of academic success (Graham \& Harris, 2005) because it can help writers to remember, to observe, to think, and to communicate (Barrass, 1995); it is also considered to be the de-rigueur penchant of those striving toward job promotion. However, English writing is a skill that many acknowledge cannot be attained without some difficulty and remains unobtainable for a majority of EFL students (Lee \& You, 2005) since the reality of the writing process is not something that can be memorized, as though it were a static and established body of knowledge, but rather, a dynamic, cognitive process (Flower \& Hayes, 1980; Goddard \& Sendi, 2008; Richards \& Renandya, 2002). In order to improve EFL learners' writing ability, scholars and teachers (Goddard \& Sendi, 2008; You \& Joe, 2002) have been investigating the utility of often competing approaches to the enhancement of English writing. Prior to the mid-1960s, EFL teachers were mostly concerned with the final product of composition by employing what is aptly termed- the product approach, which emphasized the quality of final written texts; however, this approach ignored the writer's thinking process that was behind the writing itself (Hatch, 1991). This approach subsisted until the mid-1960s, whence numerous cognitive experts uncovered what they believed to be the very thing "...that guides the decisions writers make as they write" (Flower \& Hayes, 1981, p. 365) with such 'insight' into the writing process a theory developed that was to become known as the process writing approach (Brown, 2001).

The process writing approach is a fluid process created by writers as they compose; writers can move back and forth between several stages while writing, in order to better accomplish their task (Ozagac, 2004). In an early study, Flower and Hayes (1980) proposed a cognitive process writing model, which is still considered one of the seminal pieces of research in the field of writing today (Moran \& Soiferman, 2010). Their research focused on the strategies experienced writers make use of when composing, and Flower and Hayes (1980) identified three main processing demands: the writing environment, the writer's long-term memory, and the writing process. Once writers develop their own understanding of the writing process and are better able to monitor their writing back and forth recursively, they can become more efficient at writing (Moran \& Soiferman, 2010). Likewise, according to previous studies (Lee \& You, 2005; Lu \& Tseng, 2004; Sitko, 1998; You \& Joe, 2002; Zhou, 2006), one way to engage students in the monitoring process is to provide instruction in metacognition, because it makes writers aware of their own cognitive processes. The additional use a series of checks and counterchecks ensures a constant monitoring of their understanding (Moran \& Soiferman, 2010).

The concept of metacognition has been defined as that particular knowledge concerned with the 'when and how', to use particular strategies for learning or problem solving; it is the 
understanding of the process of self-awareness and self-monitoring that controls and regulates one's thinking and behavior (Brown, 2000; Flavell, 1976; Lu \& Tseng, 2004; Zhou, 2006). In other words, metacognition generally involves both metacognitive knowledge and metacognitive behavior. Metacognative knowledge means knowing what one knows, and metacognitive behavior, means manipulating appropriately what one knows (Lu \& Tseng, 2004). According to research conducted previously (Chao, 1993; Flower \& Hayes, 1981; You \& Joe, 2001; Zhou, 2006), the whole writing process can be regarded as an operation of metacognitive behavior since writers not only know their writing strategies, but are also able to automatically manipulate them appropriately in different situations (Chin, 2003; Kauffman, $\mathrm{Ge}, \mathrm{Xie}, \&$ Chien, 2008). More specifically, writers must learn how to plan, organize, draft, revise, and edit; and to consider audience, purpose, and genre during the writing process (Hacker, 1998).

\section{Purpose of Study}

Although previous studies (Chao, 1993; Flower \& Hayes, 1981; Kauffman et al., 2008; Lynch, 1998; Lu \& Tseng, 2004; Maki, 2006; Victori, 1999; You \& Joe, 2001, 2002) have shown different metacognitive writing behavior among students with different English proficiency levels, there have been fewer studies focusing on examining the impact of metacognitive behavior in the Taiwanese learning context, that is, until recently (Chin, 2003; Liao, 2005; You \& Joe, 2001, 2002; Zhou, 2006). Therefore, the purpose of this study is to investigate the relationship between English writing ability levels and EFL learners of metacognitive behavior during the writing process, and further to explore their attitudes toward their metacognitve operations in the writing process. Three main research questions are addressed:

1. Is there a significant difference between students with different English writing ability levels and their metacognitive writing behavior in terms of planning, translating, and reviewing?

2. What is the degree of prediction between students' English proficiency levels and their metacognitive writing behavior?

3. What are students' perceptions toward their application of metacognitive behavior in the writing process?

\section{Literature Review}

\section{Flower and Hayes' Model of Writing Process}

Flower and Hayes $(1980,1981)$ discriminated three main parts for processing writing, including the task environment, the writer's long-term memory, and the writing process. The task environment includes "all of those things [factors which are related to writing] outside the writer's skin, starting with the rhetorical problem or assignment and eventually including the growing text itself" (Flower \& Hayes, 1981, p. 369); that is, the task environment refers to every possible factor that may influence the written text such as the topic, the audience, and any motivational factors (McCurdy et al., 2010). For example, before writing, the writer has to clarify the topic that he/she is going to focus on, the audience that he/she is going to write to, and the purpose of the writing. If the writer cannot identify those issues in advance, the overall quality of the written text will be poor because the writer does not know what to write, why to write, how to write, and to whom he/she is going to write (Chen, 2003).

The writer's long-term memory is "the memory in which the writer has stored knowledge, not only of the topic, but of the audience and of various writing plans" (Flower \& Hayes, 1981, 
p. 369). In other words, the writer's long-term memory refers to the writer's prior knowledge of the topics (Hayes \& Flower, 1983), as well as the strategy about how to complete the writing task (McCurdy et al., 2010). All the knowledge is stored in the writers' long-term memory. This is the phase when the writer retrieves the relevant information such as experiences, structures, and grammatical forms from the long-term memory for planning, translating, and reviewing. If the writer fails to reconstruct the stored information to meet the goal of writing, the composition may be incoherent (Chen, 2003).

The writing process, which is the main emphasis of the present study, consists of three major processes: planning, translating, and reviewing. The function of planning is to take the information from the task environment and from long-term memory to establish a writing plan to meet the goal of writing (Flower \& Hayes, 1980, 1981; Hayes \& Flower, 1983). The planning process consists of generating, organizing, and goal-setting sub processes. In terms of generating, the writer retrieves relevant information from long-term memory. After generating the ideas, the writer selects the most useful information and then organizes it to make the writing plan systematic (Lu \& Tseng, 2004). The goal-setting process identifies and stores some criteria for later use in editing. Likewise, in the translating process, the writer takes ideas from memory under the guidance of the writing plan and to transform it into acceptable written sentences (Hayes \& Flower, 1983). At this stage, the writer ought to think about the structure of the content, paying attention to the specific language use and grammar rules. Finally, the function of the reviewing process is to improve the quality of the written text by reading and editing. The writer reads through the text either to expand or revise the text produced during the translating process. Besides all of the above, the writer should also evaluate or revise the writing plan, if this proves necessary (McCurdy et al., 2010; Zhou, 2006).

\section{Metacognitive Behaviors in Writing}

Metacognitive behavior refers to how writers use various strategies of self-planning, selfrevising, self-evaluating, self-regulating, and so on when composing; such applications and reflections ought to attend the production of the text at all stages and at all times throughout the writing process, by evidencing such behaviors writers may lay claim to writing ability (Kieft, Rijlaarsdam, Galbraith, \& Bergh, 2007; Lu \& Tseng, 2004, Zhang, 2007). In other words, metacognitive behaviors indicate that writers have developed their own understanding of the composing process and are thus more able to monitor their writing (Moran \& Soiferman, 2010). Based on Flower and Hayes' (1980) model of the writing process, writers do not follow a linear path; in fact, they keep going back and forth to different sections of their paper until they complete the paper. To be more specific, mentacognitive behaviors are defined as (1) the strategies that writers use in their planning process; $(2)$ the strategies that writers use by themselves for solving problems in the translating process; (3) the strategies that writers use for self-evaluating and self-revising in the reviewing process. During the planning process, writers know how to search and organize the information related to the topic from their longterm memory. In the translating process, writers check the text to follow the writing goals, correct their own errors, and look for solutions when encountering difficulties. In terms of reviewing process, writers evaluate their overall writing performance to see how well they have done and to check whether the text corresponds with their original plan. Writers may then revise their written text if it is necessary. 
More and more researches have been conducted to investigate the effect of applying metacognitive behaviors on writing development (El-Hindi, 1993; Hayes \& Flower, 1983; Lee \& You, 2005; Scardamalia \& Bereiter, 1987; Zhou, 2006). It is found that inexperienced writers can become more adept at monitoring their writing processes when provided with good instructional approaches (McCutchen, 1996). With the help of instructors who provide the needed intervention for the many writing processes, inexperienced writers can internalize the processes that are used by more experienced writers (Moran \& Soiferman, 2010). For example, Zhou (2006) designed a training program to guide EFL senior high school students in how to do the brainstorming of ideas, set goals (about what, who, why, and how), to organize outlines, as well as develop ideas in the planning stage. Furthermore, a checklist was developed to examine whether those ideas, organization, words, and grammar were appropriate in the translating stage. After writing, a self-evaluation worksheet was provided to check if the reader understood the written text, if writer's writing achieved the goal, and if the text needed to be revised or not, etc. After six weeks of such interventional strategies, the results showed that there were significant improvements in English writing in terms of content, organization, vocabulary, language use, and mechanics. In addition, Wang in (2004) conducted a research and divided English major students into an experimental group and a control group. The data was collected from writing tasks, a questionnaire, and interviews. In the pre-test, there was no significant difference between these two groups. Afterwards, the experimental group received a 12-week metacognitive training to investigate whether there was a significant difference in their writing performance. The results showed that the experimental group outperformed the control group, particularly on aspects of content and organization. It is, therefore prudent to conclude that through metacognitive training, students can improve their English writing quality by employing appropriate metacognitive strategies.

Moreover, metacognitive training is also workable for students with learning disabilities (Chalk, Hagan-Burke, \& Burke, 2005; Da La Paz, Owenm, Harris, \& Graham, 2000). Goddard and Sendi (2008) applied metacognitive behaviors to $4^{\text {th }}$ grade students with learning disabilities. Instructors guided participants to brainstorm their ideas by taking notes in the planning stage, to count the number of words that they wrote in the translating stage, and finally self-evaluate punctuation, capitalization, indenting, topic sentences, supporting sentences, and concluding sentences in the reviewing stage. Results showed a statistically significant increase in both writing quantity and quality. It suggests that once students are trained and guided through metacognitive intervention, they would be able to operate those strategies consciously and then go on to do so automatically thus integrating those writing processes (Palinscar \& Brown, 1986).

\section{Characteristics of Metacognitive Behaviors between High-and Low-Proficient EFL Writers}

Planning. In the planning stage, high-proficient writers spend more time in planning and are more concerned about detailed information than low-proficient writers. Sasaki in (2000) investigated $12 \mathrm{EFL}$ learners writing processes by using multiple data collection procedure including their written texts, videotaped pausing behaviors while writing, and analytic scores given to the written texts. The Japanese EFL writers with different proficiency levels were compared between their behaviors while writing and their use of strategy. The results revealed that before writing, high-proficient writers spent much more time in making a global outline including planning detailed and overall organization of the composition, but low- 
proficient writers did not. After a 3.5 year of observation, the author found that, as the L2 writers became more proficient in their L2 writing, they changed their metacognitive behaviors from local planning (briefly organizing the ideas) toward more global planning. Accordingly, good writers spend more time in planning and are more concerned about information that is as detailed as possible, such as main ideas and supporting examples, as well as the whole organization of the text (Goddard \& Sendi, 2008; Larios, Manchón, Murphy, \& Marín, 2008; Liao, 2005; Mu \& Carrington, 2007; Peterson-Karlan et al., 2008; Sasaki, 2004; Zamel, 1983).

In addition, high-proficient writers tend to make a plan in L2, but low-proficient writers prefer to make it in L1. Baker and Boonkit in (2004) aimed to identify the metacognitive behaviors used between 40 successful and 67 unsuccessful learners in Thailand. The data was collected through a self-developed strategy questionnaire, student's learning journals, and interviews. The results showed that the successful writers tended to make an outline in English, while the unsuccessful writers intended to start writing immediately without planning or sometimes they made notes or rough plans in the Thai language. It is shown that high-proficient writers prefer using English to do their planning, whereas low-proficient writers seldom make a plan or directly write down in their native language while planning.

Furthermore, compared with low-proficient writers, high-proficient writers spend more time in evaluating their plan before writing. Chin (2003) conducted a study regarding the relationship between $14 \mathrm{EFL}$ university writers and their metacognitive behaviors. The top three students were compared with the lowest three. The result showed that the behavior of outlining was only used by the writers with a high proficiency level; high-proficient writers are apt to notice and evaluate the organization and structure related to the topic. Such a result supports study of Victori's (1999), indicating that low-proficient writers spend less time in planning and fail to use monitoring and evaluating strategies during the planning stage; that is, they write based solely on the inspiration of the moment.

Moreover, high-proficient writers concern themselves much more with issues regarding readers, genres, and content, than low-proficient writers, while also setting goals in the planning stage (Scardamalia \& Bereiter, 1987). Chen in (2003) investigated 20 high school student's writing processes and their metacognitive behaviors between students with different writing ability levels. The results showed that students with a high writing ability frequently used more strategies in preplanning, organizing, and setting goals in the planning stage; they were more concerned about their prospective readers as compared to those with low writing ability when making a plan. The result is similar to MacArthur and Graham's study (as cited in Chalk et al., 2005), showing that low-proficient writers simply write whatever comes into their mind without taking audiences or readership into consideration (PetersonKarlan et al., 2008).

Translating. In the translating stage, high-proficient writers tend to monitor every level of composition, while low-proficient writers seldom monitor what they write or they just check the mechanical levels. Raimes (as cited in Chen, 2003) conducted a study with eight ESL lowlevel writers. The results showed that in the translating stage, low-level writers tend to reread their sentence or the previous two or three sentences to ensure that there is no sentence fragmentation; however, they ignore the unity of the whole text which may well affect reader 
comprehension. Further Raimes in (1990) investigated the writing strategies used by the same group of eight low-level EFL writers. A questionnaire, a writing assessment, and a think-aloud technique were employed to explore their compositional behavior in the process of writing. Raimes (1990) found that though the low-proficient writers were attentive to the task, they did not monitor the whole process of writing, nor go back to read the composition because they considered that it was unavoidable to make errors in second language writing (Lu \& Tseng, 2004). Moreover, Kasper (1997) conducted a study to investigate 120 international ESL students' metacognitive behaviors, and the research found that the low-proficient writers seldom monitor their texts in relation to word selection, coherence, organization, and reader's needs due to their insufficient English writing ability. This lack of ability to monitor the text while composing affects the overall writing performance of such students (Moran \& Soiferman, 2010).

Regarding high-proficient writers, they tend to monitor their composition to see if it matches their original plan while they are translating (Hayes \& Flower, 1983; Lee \& You, 2005). For example, You and Joe $(2001,2002)$ proceeded to investigate successful writers' metacognitive behaviors of English composition by means of retrospective interviews. The researchers indicated that during the stage of translating, successful writers mastered the skills of checking the content and generating ideas as they follow their plan. In addition, Chao in (1993) explored how the writers' metacognitive behaviors affected their writing performance. By applying an interview and a writing test to 27 freshmen in one university, the researcher found that high-level writers not only noticed vocabulary and grammatical errors while composing, but also paid more attention in monitoring their text to see if it followed the original plan. However, low-level writers only monitored their mechanical errors, such as spelling, capitalization, and punctuation (Baker \& Boonkit, 2004; Chen, 2003; Larios et al., 2008; MacArthur, Graham, Schwartz, \& Schafer, 1995).

High- and low-proficient writers also show their differences in the way they solve problems while translating. In Wu's (2007) study, she investigated the writers' different metacognitive behaviors when encountering difficulties in writing. The data was collected and analyzed via a questionnaire survey and interviews. These results showed that when EFL writers encounter difficulties regarding how to make sentences or words, high- and low-proficient writers both consult a dictionary for correct usage. However, the major difference between these two groups is that more low-proficient writers chose to write the word in Chinese first, and they tried to look for an appropriate English word later. Moreover, most low-proficient writers simplified what they wanted to write if they were not sure how to express their ideas in English. Kasper (1997) mentioned that more low-proficient writers also choose to look for assistance from their friends with a higher English proficiency level instead of solving problems on their own. On the other hand, high-proficient writers directly delete their ideas when they are not able to develop those ideas further, and then they start to come up with another new idea to complete the writing task (Chen, 2003).

Reviewing. In the reviewing stage, low-proficient writers only evaluate and revise the mechanical errors in their composition since they consider it unavoidable to make errors in their second language writing (Monahan, 1984; Raimes, 1990; Wu, 2007). Baker and Boonkit (2004) examined the use of different metacognitive writing behaviors among 149 college students. The students were separated into successful and unsuccessful learners based on 
their writing scores. The data was collected via a questionnaire, student's learning journals; the data was analyzed by a t-test technique. The results showed that when unsuccessful writers finish their composition, they tend to hand in the paper immediately without checking grammar, vocabulary, spelling, punctuation, and so on. Besides, Chen (2003) investigated the different behaviors used in the writing process between 10 high-proficient writers and 10 lowproficient writers in one high school. A think-aloud technique and semi-structure interviews were applied in this study. During the reviewing process, the author found that all of the highproficient writers evaluated their compositions, and $90 \%$ of them revised their mistakes to produce a better writing performance, while only $10 \%$ of the low-proficient writers did so. Perl (as cited in Chen, 2003) also found that in the revising process, most of the less-successful writers would mainly focus on changing mechanical forms, such as additions, spellings, deletions, word choices, verbs, and punctuation, rather than clarifying the meaning of the content. In all, though low-proficient writers pay attention to evaluating the mechanical errors in their written text instead of the content, they find out not to correct their mistakes due to a lack of English language proficiency (Chalk et al., 2005). It is, therefore, concluded that low-proficient writers lack the ability of doing self-evaluation and self-revision after writing because they think that it is unavoidable to make errors in their efforts at second language writing (Raimes, 1990).

On the contrary, high-proficient writers frequently review the local and global parts in their texts, and they also polish their rhetoric during the stage of reviewing (You \& Joe, 2001, 2002). Lynch (1998) investigated the writing behaviors by four high-proficient writers at $7^{\text {th }}$ grade responding to explanatory tasks from the Maryland Writing Test (MWT: direct writing assessment consisting of two sub-tests, explanatory, and narrative). The data was collected by a think-aloud technique. It is found that high-proficient writers spent more time in revising $(46 \%)$ than translating $(41 \%)$ and prewriting (13\%). These strategies that the high-proficient writers used in the revising stage included checking the text, words, sentences, paragraphs, and global concern (e.g., changing or commenting the overall paper regarding topic, audience, form, purpose, organization, and overall quality). Such a result confirms Chin's (2003) research, investigating the effect of metacognitive behavior instruction on the development of EFL writing for 14 college freshmen. The findings showed that reviewing is the strategy employed only by the effective writers; they focus on potential problems of grammar, vocabulary use, organization of the structure, and content. In other words, highproficient writers are used to revising their composition by checking grammar, spelling, topic, audience, and textual purpose, after finishing the composition of the text (Chalk et al., 2005; Chen, 2003; Hayes \& Flower, 1983; Mu \& Carrington, 2007; Scardamalia \& Bereiter, 1987; Yagelski, 1995; You \& Joe, 2000, 2001, 2002; Zamel, 1983).

\section{Methodology \\ Subjects}

Subjects in this study were 152 students, including 51 males and 101 females, from freshmen to juniors, majoring in Applied English at one university in the south of Taiwan. A demographic questionnaire was provided to collect subjects' background information including their grade level, age, gender, and years of learning English. The subjects ranged in ages from 18 to 23 years old, with an average of 19.94 years old; they had been receiving English learning for an average of 9.63 years. The detail of the demographic information is shown in Table 1. 
INTERNATIONAL JOURNAL OF ACADEMIC RESEARCH IN PROGRESSIVE EDUCATION AND

DEVELOPMENT

Vol. 1, No. 4, 2012, E-ISSN: 2226-6348 @ 2012 HRMARS

Table 1 Demographic Information of Subjects

\begin{tabular}{lllllll}
\hline Grade & $\mathrm{N}$ & \multicolumn{2}{l}{ Gender } & Age & $\begin{array}{l}\text { Years of Learning } \\
\text { English }\end{array}$ & \\
\cline { 3 - 4 } & & $\mathrm{M}$ & $\mathrm{F}$ & & 20.89 & 9.89 \\
Junior & 35 & 6 & 29 & 19.79 & 9.41 & \\
Sophomore & 94 & 38 & 56 & 19.13 & 9.60 & \\
Freshman & 23 & 7 & 16 & 190 & & \\
Total & 152 & 51 & 101 & & &
\end{tabular}

To evaluate students' writing ability levels, a writing test was conducted in the spring semester of 2011. Subjects were asked to write a composition within 30 minutes. The writing results were assessed by writing evaluation software called "CorrectEnglish" to categorize subjects into three writing ability levels based on the Flesch-Kincaid Grade Level: high level (top 27\%), intermediate level (46\%), and low level (bottom 27\%) (Guo, 1998). The scores in the writing test for those 152 subjects ranged from 3.40 to 12.00 , with the mean score of 6.84 $(S D=2.25)$. Forty-two subjects (top $27 \%$ ) were labeled as high-proficient writers $(M=9.13$, $S D=1.33)$; 68 subjects $(46 \%)$ were labeled as intermediate-proficient writers $(M=6.87$, $S D=.51$ ), and 42 subjects (bottom 27\%) were labeled as low-proficient writers $(M=5.32$, $S D=.65)$. There was a significant difference between the high- and low-proficiency levels, indicating that the high-proficient writers scored significantly higher than the low-proficient writers. The details of the group classifications are shown in Table 2.

Table 2 Classification of Three Groups

\begin{tabular}{llllll}
\hline Level & $\mathrm{N}$ & Rate $\%$ & $\begin{array}{l}\text { Scores' } \\
\text { Range }\end{array}$ & $\mathrm{M}$ & SD \\
\hline High & 42 & $27 \%$ & $7.80^{\sim} 12.00$ & 9.13 & 1.33 \\
Intermediate & 68 & $46 \%$ & $6.10^{\sim} 7.70$ & 6.87 & .51 \\
Low & 42 & $27 \%$ & $3.40^{\sim} 6.00$ & 5.32 & .65 \\
Total & 152 & $100 \%$ & $3.40^{\sim} 12.00$ & 6.84 & 2.25 \\
\hline
\end{tabular}

\section{Sampling Strategies}

For quantitative sampling, multistage sampling which is one of the probability sampling strategies, including cluster sampling and random sampling was used to select the subjects (McMillan \& Schumacher, 2006). For convenience and time saving, cluster sampling, which is used with naturally occurring groups of individuals, was applied in the first step to select students majoring in Applied English at one university in the south of Taiwan. Afterwards, random sampling was employed to select samples from those populations. Each population was given a code, and then the researcher put those numbers in a box, selecting them out at random to be the subjects. To make sure that all of the subjects have experiences of utilizing metacognitive strategies while writing, four pre-questions (item 1, 2, 15, 31) were asked within a questionnaire in advance. Finally, 152 subjects in total ( 23 freshmen, 94 sophomores, and 35 juniors) were chosen to participate in the study. Those subjects were asked to write a composition and fill in the questionnaire to obtain self-reports toward their metacognitive behaviors in the writing process.

For qualitative sampling, in order to understand the perceptions between different proficientlevel writers toward the application of metacognitive behaviors in the writing process, 
stratified purposeful sampling, choosing participants based on the specific proficiency level, was employed to explore participants' expressions (McMillan \& Schumacher, 2006). Fifteen participants in total (five from each level) were chosen randomly from those 152 students who had experiences of using their metacognitive strategies while writing. Those 15 participants were interviewed to collect their opinions for qualitative analysis. To sum up, 15 out of 152 participants were selected randomly to explore their perceptions toward their metacognitive operations in the writing process.

\section{Instrumentation}

A Composition Test. In order to classify the subjects' writing ability levels, each subject was asked to write an English composition in the spring semester of 2011. The topic of the composition is "What is Your Favorite Chinese Festival" because Yu (2006) mentioned that this topic is related to Taiwanese festivals and culture, students are familiar with it and thus suffer less from cultural interference. Subjects were given 30 minutes to finish the writing task on a computer. Under time limitation, students were expected to concentrate more on their writing. Subjects then sent their text to the researcher via e-mail after finishing the composition, and the researcher copied each subject's writing and pasted it to software called "CorrectEnglish" for scoring and categorizing.

The software "CorrectEnglish" was designed to help writers improve their overall writing quality instantly by checking grammar, style, and proper word usage; this software provides a holistic score and immediate feedback on content, organization, style, and overall performance (Summit IntelliMetric, 2008). In this study, the software "CorrectEnglish" was used as an instrument to classify the subjects' writing ability into three discriminative levels based on the Flesch-Kincaid Grade Level. Flesch-Kincaid Grade Level is a valid and reliable language readability formula to test the readability of written texts. The Flesch-Kincaid grade level is calculated by using the formula: $(0.39 \times$ average sentence length $)+(11.8 \times$ average number of syllables per word) - 15.59 (Darus, Ismail, \& Ismail, 2008). According to the previous studies (Cleaveland \& Larkins, 2004; Darus et al., 2008; Perin et al., 2003; Shang, 2007), lower scores characterize text that is more difficult to read and roughly corresponds to lower writing ability, lower literacy level, as well as poor writing quality.

A Questionnaire. A questionnaire was designed in this study to investigate the subjects' selfreports toward their metacognitive behaviors in the writing process. Three stages of writing process in terms of planning, translating, and reviewing were included in the questionnaire. In this study, the planning process means taking the information from long-term memory to make a writing plan; generating, organizing, and setting goals are included. The translating process refers to taking ideas from memory under the guidance of the writing plan and to transform them into acceptable written sentences. Reviewing is the process of examining what the writer puts into words and revising them if necessary. Forty-three items, 4 items in the pre-questioning checklist section, 12 items in the planning section, 15 items in the translating section, and 12 items in the reviewing section, were composed for the purposes of this questionnaire. To aid in a better understanding of those items, each subject had the right to choose the questionnaire either in an English or Chinese version. The items of the questionnaire were adapted based on Lu and Tseng's (2004) Form of Metacognitive Behaviors in Writing Process and Wu's (2007) Writing Strategies Questionnaire. A five-point Likert scale ranging from " 5 " (always) to " 1 " (never) was applied to examine the subjects' perceptions 
toward the frequency of their metacognitive behavior use. A pilot study was tested by six students, including two juniors, two sophomores, and two freshmen, majoring in Applied English to ensure that each item was more readable. After the pilot test, items 7, 8, 17, and 22 were provided with explicit examples to clarify the meaning of each of the items.

To check the validity and reliability of the questionnaire, each questionnaire item was examined using the software, SPSS (Statistical Packages for the Social Sciences) 17.0 version. The independent sample $t$-test was used to examine the validity. Thirty-nine items, excluding 4 items in the pre-questioning checklist section, were retained since there was a significant difference $(p<.05)$ among them. For reliability, the Cronbach alpha $(\alpha)$ was computed to examine the internal-consistency reliabilities of the questionnaire. The value of Cronbach alpha ( $\alpha$ ) can range from 0 to 1 ; if $\alpha>.70$, there is a high reliability among the questionnaire items. The results of Cronbach internal-consistency coefficients for planning, translating, and reviewing are $.79, .81$, and .90 , respectively, indicating that there is a high reliability among the questionnaire items. The detailed information is shown in Table 3.

Table 3 Results of Cronbach Internal-Consistency Coefficients

\begin{tabular}{lll}
\hline Type & N of Items & Cronbach's Alpha \\
\hline Planning & 12 & .79 \\
Translating & 15 & .81 \\
Reviewing & 12 & .90 \\
\hline
\end{tabular}

Note. Total Numbers of Items $=39$

A Semi-Structured Interview. Fifteen participants who were chosen from the 152 subjects were interviewed by using a semi-structured interview technique; that is, though the interview questions had been composed in advance, more follow-up questions can still be raised according to the participants' responses, in order to provide more complete information (McMillan \& Schumacher, 2006). In other words, by using the semi-structured interview, participants' perceptions toward their metacognitive writing operations could be explored. Five participants from each proficiency level were selected randomly for the interview. In order to get participant's permission, they were informed by a consent form, showing the purpose and the process of this research; they had the right not only to ignore the sensitive questions, but also to withdraw from the interview process at any time. Additional care was taken to protect identities of participants by substituting names with numbers.

There were 13 interview questions in total; which focused on exploring the participant's past and present experiences, and their perceptions toward their metacognitive behaviors in the writing process. Each participant was interviewed for about 20 to 30 minutes. During the process of the interview, each participant could answer the interview questions either in English or Chinese language depending on which language they preferred. A pilot study was done and modified by the first two participants to ensure the clarity of the interview questions. 


\section{Data Collection Procedures}

Owing to time limitations, the pragmatic parallel-mixed method was applied in this study (Chin, 2003); that is, the quantitative and qualitative data were collected simultaneously or with as short a time-lag as possible (McMillan \& Schumacher, 2006). During the process of data collection, the subjects in the courses of "English Composition," "Essay Writing," and "Research Paper Design" were taken to the computer room to write a composition within 30 minutes in the spring semester of 2011. Afterwards, the subjects were asked to send their compositions to the researcher via e-mail. The researcher collected the subjects' compositions and pasted them to the software "CorrectEnglish" for categorizing subjects into three writing ability levels based on Flesch-Kincaid Grade Level. Then, the subjects were required to fill in the questionnaire immediately after finishing their compositions.

After the process of quantitative data collection, the qualitative research method was conducted immediately to get the participants' self-perceptions toward their metacognitive writing behaviors. Five participants from each group were selected randomly to participate in the semi-structured interview. A tape recorder was used to collect participants' perceptions. Moreover, participants' responses were transcribed by the researcher for further data analyses.

\section{Data Analysis Procedures}

In this study, both quantitative and qualitative research techniques were utilized to explore subjects' self-reports of their metacognitive operations. Three research questions are addressed in the following: (1) Is there a significant difference between students with different English writing ability levels and their metacognitive writing behaviors in terms of planning, translating, and reviewing? (2) What is the degree of prediction between students' English writing ability levels and their metacognitive behaviors in the writing process? (3) What are students' perceptions toward their application of metacognitive behaviors in the writing process?

For quantitative research, in order to analyze the difference of student's English writing ability levels on their operations of metacognitive behaviors, a one-way analysis of variance (ANOVA), which the independent variable (IV) is the subjects' writing ability levels and the dependent variable (DV) is their reports toward the metacognitive writing behaviors in terms of planning, translating, and reviewing stages, was conducted to analyze whether subjects with different English writing ability levels have significant differences in their metacognitive writing behaviors.

In addition, a multiple regression analysis was used to investigate the degree of prediction between the writing ability levels of students and their reports concerning metacognitive writing behaviors (McMillan \& Schumacher, 2006). The stepwise regression, which combines forward regression (if $r$ is larger and $p \leqq .05$, then enter the variable in the regression model) and backward regression (if $F<2.71$ or $p \geqq .01$, then eliminate the variable), was conducted in the multiple regression analysis (McMillan \& Schumacher, 2006).

A semi-structured interview technique was applied to obtain participants' information about their perceptions toward the application of metacognitive behaviors in the writing process. A 
tape recorder was used during the interview process. The opinions of participants were then transcribed by the researcher to analyze participants' perceptions regarding their metacognitive writing behaviors. After transcribing, the content which is related to the purpose of this study was marked and labeled for further content analyses to form a grounded theory.

\section{Results}

Research question 1: Is there a significant difference between students with different English writing ability levels and their metacognitive writing behaviors in terms of planning, translating, and reviewing?

The descriptive statistics of mean scores and standard deviations among different English writing ability levels in respect to the aspect of planning is shown in Table 4 . The result shows that high-proficient writers $(M=3.70, S D=.48)$ employ more planning strategies than intermediate-proficient $(M=3.46, S D=.52)$ and low-proficient writers $(M=3.33, S D=.50)$. Moreover, low-proficient writers $(M=3.67, S D=1.14)$ tend to make an outline in Chinese than high-proficient writers $(M=3.14, S D=1.16)$. On the other hand, high-proficient writers $(M=$ $3.48, S D=.74)$ prefer making an outline in English, whereas low-proficient writers do not $(\mathrm{M}=2.93, \mathrm{SD}=1.05)$.

Table 4 Use in the Planning Stage among Different Writing Ability Levels

\begin{tabular}{|c|c|c|c|c|c|c|}
\hline \multirow[t]{2}{*}{ Planning } & \multicolumn{2}{|c|}{$\begin{array}{l}\text { High } \\
N=42\end{array}$} & \multicolumn{2}{|c|}{$\begin{array}{l}\text { Intermediate } \\
\mathrm{N}=68\end{array}$} & \multicolumn{2}{|c|}{$\begin{array}{l}\text { Low } \\
N=42\end{array}$} \\
\hline & M & SD & $\mathrm{M}$ & SD & $M$ & SD \\
\hline 3. roughly generate ideas & 3.76 & .96 & 3.62 & .91 & 3.62 & .85 \\
\hline 4. generate ideas completely & 3.83 & .91 & 3.34 & .87 & 3.33 & .95 \\
\hline 5. briefly organize content & 3.93 & .92 & 3.53 & .95 & 3.55 & .99 \\
\hline 6. organize content in detail & 3.70 & .87 & 3.59 & .95 & 3.24 & .96 \\
\hline 7. Chinese outline & 3.14 & 1.16 & 3.28 & 1.12 & 3.67 & 1.14 \\
\hline 8. English outline & 3.48 & .74 & 3.25 & .85 & 2.93 & 1.05 \\
\hline 9. setting a goal based on the topic & 4.02 & .84 & 3.71 & .83 & 3.55 & .89 \\
\hline $\begin{array}{l}\text { 10.setting a goal based on audience's } \\
\text { needs }\end{array}$ & 3.45 & 1.04 & 3.16 & .94 & 2.93 & .89 \\
\hline 11. setting a goal based on the genre & 3.50 & 1.06 & 3.16 & 1.05 & 2.93 & 1.02 \\
\hline 12. matching the topic & 4.02 & .64 & 3.76 & .81 & 3.60 & .66 \\
\hline 13. suitable order & 3.93 & .75 & 3.57 & .94 & 3.31 & .78 \\
\hline 14. no planning* & 2.36 & .93 & 2.43 & 1.00 & 2.64 & .93 \\
\hline Average & 3.70 & .48 & 3.46 & .52 & 3.33 & .50 \\
\hline
\end{tabular}

Note. $\mathrm{N}=152, *$ reversed questionnaire item

The descriptive statistics of mean scores and standard deviations among different English writing ability levels on the aspect of translating is shown in Table 5. The results indicate that high-proficient writers $(M=3.76, S D=.44)$ generally employ more translating strategies, followed by intermediate-proficient writers $(M=3.56, S D=.53)$, and then followed by low- 
proficient writers $(M=3.55, S D=.47)$. It is, nevertheless, obvious to find that there is no major difference for each mean score among different writing ability levels.

Table 5 Use in the Translating Stage among Different Writing Ability Levels

\begin{tabular}{|c|c|c|c|c|c|c|}
\hline \multirow[t]{2}{*}{ Translating } & \multicolumn{2}{|c|}{$\begin{array}{l}\text { High } \\
n=42\end{array}$} & \multicolumn{2}{|c|}{$\begin{array}{l}\text { Intermediate } \\
n=68\end{array}$} & \multicolumn{2}{|c|}{$\begin{array}{l}\text { Low } \\
n=42\end{array}$} \\
\hline & $\mathrm{M}$ & SD & $\mathrm{M}$ & SD & $\mathrm{M}$ & SD \\
\hline 16. sentence fragment & 3.57 & 1.02 & 3.25 & .97 & 3.40 & .94 \\
\hline 17. word spelling & 3.89 & .92 & 3.59 & .88 & 3.62 & .94 \\
\hline 18. grammar & 3.48 & .80 & 3.47 & .85 & 3.33 & .93 \\
\hline 19. punctuation & 3.60 & .83 & 3.46 & .94 & 3.24 & .95 \\
\hline 20. structure & 4.07 & .95 & 3.62 & .98 & 3.43 & .86 \\
\hline 21. word choice & 4.02 & .72 & 3.85 & .87 & 3.76 & .85 \\
\hline 22. content matches the topic & 3.86 & .75 & 3.81 & .87 & 3.60 & .77 \\
\hline 23. content matches the plan & 3.67 & .65 & 3.50 & .84 & 3.31 & .84 \\
\hline $\begin{array}{l}\text { 24. reread to continue the next } \\
\text { sentence }\end{array}$ & 4.00 & .91 & 3.93 & .89 & 4.07 & .75 \\
\hline 25. simplify the sentence & 3.71 & 1.13 & 3.46 & 1.01 & 3.33 & 1.10 \\
\hline 26. check up in the dictionary & 4.14 & .81 & 3.81 & 1.15 & 3.79 & 1.14 \\
\hline 27. write in Chinese first & 3.62 & 1.29 & 3.41 & 1.22 & 3.67 & 1.18 \\
\hline 28. ask friends for help & 3.76 & 1.05 & 3.49 & 1.09 & 3.79 & .92 \\
\hline $\begin{array}{l}\text { 29. delete the ideas and develop } \\
\text { another one }\end{array}$ & 3.31 & 1.00 & 3.32 & .89 & 3.50 & .86 \\
\hline 30. do not check* & 2.29 & .92 & 2.50 & .91 & 2.62 & .88 \\
\hline Average & 3.76 & .44 & 3.56 & .53 & 3.55 & .47 \\
\hline
\end{tabular}

Note. $\mathrm{N}=152, *$ reversed questionnaire item

The descriptive statistics of mean scores and standard deviations between different English writing ability levels and the reviewing stage is shown in Table 6. The results reveal that highproficient writers $(M=3.88, S D=.53)$ frequently employ more reviewing strategies than intermediate-proficient writers $(M=3.53, S D=.61)$, and then followed by low-proficient writers $(M=3.40, S D=.65)$. The major difference among them is in relation to aspects of evaluating global errors and figuring out mistakes. 
Table 6 Use in the Reviewing Stage among Different Writing Ability Levels

\begin{tabular}{|c|c|c|c|c|c|c|}
\hline \multirow[t]{2}{*}{ Reviewing } & \multicolumn{2}{|c|}{$\begin{array}{l}\text { High } \\
n=42\end{array}$} & \multicolumn{2}{|c|}{$\begin{array}{l}\text { Intermediate } \\
n=68\end{array}$} & \multicolumn{2}{|l|}{$\begin{array}{l}\text { Low } \\
n=42\end{array}$} \\
\hline & $M$ & SD & M & SD & M & SD \\
\hline 32. word spelling & 4.05 & .85 & 3.71 & .96 & 3.95 & .96 \\
\hline 33. the appropriate word & 4.10 & .79 & 3.67 & .96 & 3.71 & 1.02 \\
\hline 34. grammar & 4.00 & .70 & 3.70 & .87 & 3.60 & 1.08 \\
\hline 35. punctuation & 3.86 & .75 & 3.54 & .95 & 3.50 & 1.09 \\
\hline 36. content fits the topic & 4.12 & .67 & 3.74 & .89 & 3.74 & .83 \\
\hline 37. the organization & 4.05 & .76 & 3.70 & .85 & 3.40 & 1.01 \\
\hline 38. content fits the planning goal & 3.74 & .83 & 3.44 & .87 & 3.26 & .96 \\
\hline 39. revise the wrong spelling & 3.90 & .93 & 3.38 & .88 & 3.20 & .99 \\
\hline 40. revise the wrong grammar & 3.50 & .89 & 3.18 & .78 & 2.64 & .93 \\
\hline 41. revise the content to fit the topic & 3.62 & .79 & 3.28 & .77 & 3.05 & .85 \\
\hline 42. reorganize the content & 3.57 & .77 & 3.24 & .88 & 2.93 & .87 \\
\hline 43. hand writing without evaluating* & 1.92 & .87 & 2.15 & 1.03 & 2.11 & 1.06 \\
\hline Average & 3.88 & .53 & 3.53 & .61 & 3.40 & .65 \\
\hline
\end{tabular}

Note. $\mathrm{N}=152, *$ reversed questionnaire item

After presenting the mean scores and standard deviations for each writing stage, a one-way analysis of variance (ANOVA) was conducted to examine whether there is a significant difference among high-, intermediate-, and low-proficient writers' self-reports in terms of planning, translating, and reviewing. Results in Table 7 reveal that there are significant differences at the .05 probability level between the stages of planning $[F(2,149)=5.875, p=$ $.003]$ and reviewing $[F(2,149)=7.406, p=.001]$ and different English proficiency levels. However, there is no significant difference between writing ability levels and translating.

Table 7 A One-way ANOVA Analyses between English Writing Ability Levels and Metacognitive Behaviors

\begin{tabular}{llllll}
\hline Metacognitive Behaviors & SS & $d f$ & MS & F & Sig. \\
\hline $\begin{array}{l}\text { Planning } \\
\text { Between groups }\end{array}$ & 2.94 & 2 & 1.47 & 5.88 & $.003^{*}$ \\
$\quad$ Within groups & 37.31 & 149 & .25 & & \\
$\quad$ Total & 40.26 & 151 & & & \\
$\begin{array}{l}\text { Translating } \\
\quad \text { Between groups }\end{array}$ & 1.26 & 2 & .63 & 2.62 & .076 \\
$\quad$ Within groups & 35.67 & 149 & .24 & & \\
$\quad$ Total & 36.93 & 151 & & & \\
Reviewing & & & & & \\
$\quad$ Between groups & 5.35 & 2 & 2.68 & 7.41 & $.001^{*}$ \\
$\quad$ Within groups & 53.82 & 149 & .36 & & \\
$\quad$ Total & 59.17 & 151 & & & \\
\hline Note:p<.05 & & & & &
\end{tabular}

Note: $p<.05$ 
Scheffé post hoc comparison procedure was further implemented to examine multiple comparisons between the means of self-reports and three proficiency levels. As shown in Table 8, high-proficient writers score significantly higher than low-proficient writers in the planning stage $(M D=.37)$, indicating that students with a higher English proficiency level tend to use more planning strategies than low-proficient writers do. In addition, in the reviewing stage, high-proficient writers score significantly higher than intermediate-proficient (MD= .53 ) and low-proficient writers $(M D=.48)$. In other words, students with a high English writing ability level report that they use more reviewing strategies than those with a low proficiency level.

Table.8 Scheffé Post Hoc Comparison between Writing Ability Levels and Metacognitive Behaviors

\begin{tabular}{lllll}
\hline $\begin{array}{l}\text { Metacognitive } \\
\text { Behaviors }\end{array}$ & Levels & $\begin{array}{l}\text { Mean } \\
\text { Differences }\end{array}$ & Sig. \\
\hline Planning & $\mathrm{H}$ & $\mathrm{I}$ & .24 & .056 \\
& & $\mathrm{~L}$ & .37 & $.004^{*}$ \\
& $\mathrm{I}$ & $\mathrm{H}$ & -.24 & .056 \\
& & $\mathrm{~L}$ & .13 & .426 \\
& $\mathrm{~L}$ & $\mathrm{H}$ & -.37 & $.004^{*}$ \\
& & $\mathrm{I}$ & -.13 & .426 \\
\hline Translating & $\mathrm{H}$ & $\mathrm{I}$ & .20 & .127 \\
& & $\mathrm{~L}$ & .21 & .141 \\
& $\mathrm{I}$ & $\mathrm{H}$ & -.20 & .127 \\
& & $\mathrm{~L}$ & .02 & .986 \\
& $\mathrm{~L}$ & $\mathrm{H}$ & -.21 & .141 \\
& & $\mathrm{I}$ & -.02 & .986 \\
\hline Reviewing & $\mathrm{H}$ & $\mathrm{I}$ & .35 & $.013^{*}$ \\
& & $\mathrm{~L}$ & .48 & $.002^{*}$ \\
& $\mathrm{I}$ & $\mathrm{H}$ & -.35 & $.013^{*}$ \\
& & $\mathrm{~L}$ & .13 & .549 \\
& $\mathrm{~L}$ & $\mathrm{H}$ & -.48 & $.002^{*}$ \\
& & $\mathrm{I}$ & -.13 & .549 \\
\hline
\end{tabular}

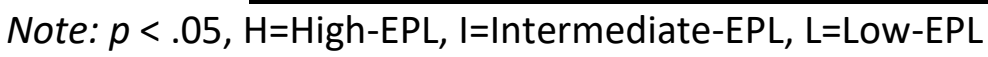

Research question 2: What is the degree of prediction between students' English writing ability levels and their metacognitive behaviors in the writing process?

This part of the study aims to investigate the extent of prediction between student's English writing ability levels and their metacognitive behaviors by employing a multiple regression analysis. The data in Table 9 shows that the factor of planning achieves a positive significant level $(\beta=.202, p=.012)$, indicating that the metacognitive behavior of planning is an influential factor toward changes in English writing ability, though the estimation of this prediction is weak $\left(R^{2}=.041\right)$. It is, therefore, concluded that the metacognitive behavior of planning is a weak influential factor that affects EFL writing ability. However, there is no significant effect between the factor of using metacognitive behaviors in translating $(p=.883)$ and reviewing $(p=.346)$. 
Table 9 Prediction between English Proficiency Levels and Writing Metacognitive Behaviors

\begin{tabular}{|c|c|c|c|c|c|c|c|}
\hline Model & $R$ & $\mathrm{R}^{2}$ & $\begin{array}{l}\mathrm{R}^{2} \\
\text { Change }\end{array}$ & $\begin{array}{l}\text { Unstandardized } \\
\text { Coefficients }\end{array}$ & $\begin{array}{l}\text { Standardized } \\
\text { Coefficients } \\
\text { (ß) }\end{array}$ & $t$ & Sig. \\
\hline constant & & & & 4.113 & & & \\
\hline 1(planning) & .202 & .041 & .041 & .882 & .202 & 2.532 & $.012 *$ \\
\hline
\end{tabular}

In terms of planning, students with different writing ability levels have different perceptions toward the process of generating ideas, making an outline, and considering reader's needs and the demands of different genres. High-proficient students frequently generate complete ideas in order to write more fluently and faster in the translating stage, but students with a low writing ability level tend to generate ideas roughly in order to save time for the translating stage. Excepting the above, a minority of students agree that the more they are familiar with the topic, the more they can generate complete ideas. In addition, students with a high writing ability level are accustomed to making an outline in English and are more acquainted with English writing structures, whereas most low-proficient students like to make an outline in Chinese so that they might express their ideas distinctly, as well as saving time for the translating stage. Moreover, students with a high proficiency level take readers' needs and the demands of genres into consideration which garners greater positive feedback for their effort. On the contrary, students with a low writing ability level, ignore the need of readers' needs and genres, since they are privy to prior reflections that deem both audience and genre as unworthy of serious attention.

In the translating stage, most students from high to low proficient writers generally have a similar set of perceptions toward their monitoring of grammar, spelling, content, and organization. Since they believe it to be unavoidable that mistakes in their second language writing will be made, students have to monitor each element more carefully when writing. Furthermore, students generally ask friends for help, simplify complex sentences, and develop new ideas when encountering problems in writing. However, few students prefer solving problems by themselves since they dislike bothering others as well as distrusting their friends' English ability. In addition, in order not to waste time nor to be interrupted during the writing process, students are used to writing down words first in Chinese for they are unsure of English words, and later they go back to look for the English translation. However, few students consider that they have to solve such problems immediately, for such attentions detract greatly from any satisfaction they might feel, concerning their writing.

In the reviewing stage, students with different writing ability levels have different points of view in terms of evaluating their writing at both mechanical and global errors. Most highproficient students are used to reviewing not only at the mechanical level such as grammar and vocabulary but also at the global level, including content and organization. Highproficient writers take reviewing as the final chance to enhance their writing quality, so they have to make sure that each detail goes well. However, most low-proficient students have a noted propensity toward focusing on reviewing the mechanical part of their writing because 
grammar and vocabulary are two main elements which may influence their writing performance. In terms of figuring out mistakes, students with a high writing ability level have more ability when it comes to finding mistakes owing to a greater willingness to seek out aids (e.g. internet, grammar book), whereas students with a low-proficiency level seldom figure out mistakes due to insufficient English ability.

\section{Discussion}

The purpose of this study is to investigate the relationship between English writing ability levels and EFL learners' metacognitive behaviors, and further, to explore their attitudes toward their metacognitive operations in the writing process. Several key findings emerged from this research. First of all, writers with a high proficiency level employ more planning strategies than those with a low-proficiency level, particularly in generating ideas, making an outline, and taking readers' needs and genres under consideration. In order to write fluently and smoothly in the translating stage, most high-proficient writers prefer generating complete ideas and organizing them well before composing. Such findings support the previous studies (e.g., Goddard \& Sendi, 2008; Larios et al., 2008; Liao, 2005; Mu \& Carrington, 2007; Peterson-Karlan et al., 2008; Zamel, 1983), indicating that high-proficient writers have concerns about a variety of elements such as main ideas and supporting details, as well as the overall organization. On the other hand, due to the worries of having insufficient time to finish writing, most low-proficient writers choose to generate main ideas briefly or jump to the translating stage directly as a time-saving strategy. This result supports previous research (e.g., Sasaki, 2000, 2004), showing that low-proficient writers have a tendency to make a local plan, such as roughly organizing ideas in their outline. Besides, in order to correspond to the English writing style, high-proficient writers try to make an outline in English, whereas lowproficient writers tend to make an outline in Chinese to express their ideas more easily. According to Beare and Bourdages (2007), students with a high proficiency level can express their ideas successfully in L2, instead of reverting to $L 1$ while writing. The findings of the present study further confirms the results of previous studies (e.g., Baker \& Boonkit, 2004; Peacock, 2001), indicating that high-proficient writers prefer making an outline in L2, yet lowproficient writers prefer making it in L1.

Secondly, writers with a high proficiency level consider readers' needs and genres to modify their plan for the sake of getting a higher score. This result matches the results of previous studies (e.g., Chen, 2003; Scardamalia \& Bereiter, 1987), demonstrating that high-proficient writers are more concerned about readers and genres during the planning stage. In contrast, part of the intermediate- and low-proficient writers considerations are that the factors of readers' needs and genres are not important since writing should not be confined. This finding supports previous studies (e.g., Chalk et al., 2005; Peterson-Karlan et al., 2008), proclaiming that low-proficient writers simply write whatever comes into their mind without taking audiences and genres into consideration. After investigating the extent of prediction between students' English writing ability levels and their metacognitive behaviors by employing a multiple regression analysis, it is obvious that metacognitive behavior at the planning stage is an important variable to predict students' English writing ability.

Thirdly, high-proficient writers employ more reviewing strategies than low-proficient writers, significantly in evaluating and figuring out mistakes. To get a high score, writers with a high proficiency level usually catch this final chance to evaluate both mechanical and global errors, 
involving the checking of content, organization, topic, and purpose for writing. In contrast, writers with a low proficiency level focus on grammar and spelling checks only, since they consider that these two elements are important for understanding and getting a high score. The results support the findings of previous studies (e.g., Chalk et al., 2005; Hayes \& Flower, 1983; Lynch, 1998; Mu \& Carrington, 2007; Scardamalia \& Bereiter, 1987; Yagelski, 1995; You \& Joe, 2000, 2001, 2002; Zamel, 1983), indicating that high-proficient writers are used to revising their text by checking errors on the mechanical and global levels, whereas lowproficient writers seldom, or only, make mechanical revisions.

Finally, high-proficient writers frequently figure out mistakes and revise them with the assistance of subsidiary materials such as grammar books and dictionaries; they also find out the solutions by searching online resources if needed. On the contrary, owing to their insufficient English ability, most low-proficient writers have difficulties in figuring out mistakes, except the obvious and superficial ones, such as spelling mistakes. This result follows previous research (e.g., Chalk et al., 2005; Chin, 2003; Lu \& Tseng, 2004; Stallard, 1974), indicating that though low-proficient writers often check the mechanical errors in their writing, they hardly find out nor correct their mistakes due to their insufficient English language proficiency.

\section{Conclusion}

Since there have been fewer studies focusing on examining the impact of metacognitive behaviors in the Taiwanese learning context (Chin, 2003; Liao, 2005; You \& Joe, 2001, 2002; Zhou, 2006), the purpose of this study is to investigate the relationship of metacognitive behaviors among EFL writers with different English proficiency levels, and further to explore their attitudes toward their metacognitive operations in the writing process. The research results reveal that writers with a high English proficiency level make better use of metacognative operations in the stages of planning and reviewing; however, there is no significant difference between writing ability levels and their metacognitive behaviors at the translating stage. Moreover, it is predicted that if students make a complete plan before writing, there is a higher possibility of their being able to enhance their writing ability. To specifically discriminate the different metacognitive writing behaviors, high-proficient writers frequently generate complete ideas, take audiences' needs and genres as considerations, and make an outline in English for the purpose of writing fluently at the translating stage; they evaluate their text both at local and global levels in the reviewing stage, and make use of any possible resources to correct their mistakes. In contrast, low-proficient writers tend to generate rough ideas with a Chinese outline; they focus on evaluating their texts on a purely mechanical level, but seldom are they able to locate those mistakes due to their insufficient English ability. It is, therefore, obvious that students with different writing ability levels generally conduct different metacognitive behaviors in the writing process (Chao, 1993; Chin, 2003; Flower \& Hayes, 1981; Kauffman, et al., 2008; Lynch, 1998; Lu \& Tseng, 2004; Maki, 2006; Victori, 1999; You \& Joe, 2001, 2002).

\section{Pedagogical Implications}

According to the research results of the present study, several pedagogical implications are offered to EFL instructors for the improvement of students' overall writing performance. To become proficient writers, it is important for EFL writing instructors to train students how to make a plan before writing since it is a significant predictor of English writing enhancement. 
To illustrate more specifically, EFL writing teachers should ask students to generate complete ideas with the consideration of audiences' needs and genres, and make an outline in English before writing. While translating, EFL instructors should demand that student's monitor their written texts at all times, including content, structure, punctuation, etc. In the reviewing stage, teachers should remind students to evaluate not only their mechanical usage, but also the textual content as well as the overall structure. EFL instructors can also suggest that students bring some reference books, like dictionaries and grammar books, while checking their compositions.

To enhance students' writing ability, few students' perceptions cannot be ignored. First of all, students have a difficulty in generating complete ideas especially so when dealing with unfamiliar topics. In other words, if the topic is not related to the students' daily life, they will generate rough ideas at most. Therefore, it is suggested that EFL teachers should select topics which are related to students' experiences in their daily life, so that they can express their ideas without interference (Yu, 2006). If the topic is irrelevant to students' experiences, teachers have to provide students with abundant background information before written compositions are attempted. When students have acquired sufficient information, they may have more ideas to add to a complete writing plan.

Secondly, some students revealed that they felt too embarrassed to ask their classmates questions and also doubted their friends' English ability when encountering problems in writing. Teachers may separate students into groups on the basis of their heterogeneity, which means that a group is comprised of students with different language proficiency levels, and then ask group members to help their partners solve problems during the writing process.

Finally, some students prefer to consult a dictionary directly for any unknown English words, while others tend to write down Chinese words first. Either way can be accepted since most students from high to low proficiency levels generally have similar study habit. It is essentially important to remind students that they ought to not only be looking for the meaning of a word, but also noticing its syntax, its semantic and pragmatic functions (Huang, 1985) so as to use the word in the most appropriate way.

\section{References}

Baker, W., \& Boonkit, K. (2004). Learning strategies in reading and writing: EAP context. Regional Language Centre Journal, 35(3), 297-328.

Barrass, R. (1995). Students must write. New York: Routledge.

Beare, S., \& Bourdages, J. S. (2007). Skilled writers' generating strategies in La and L2: An exploratory study. In M. Torrance, L. van Wase, \& D. Galbraith (Eds.), Writing and Conginition: Research and Applications (pp. 151-161). Amsterdam:Elsevier.

Brown, H. D. (2000). Principles of language learning and teaching (4nd ed.). NY: Person Education.

Brown, H. D. (2001). Teaching by principles: An interactive approach to language pedagogy (2nd ed.). NY: Person Education.

Chalk, J. C., Hagan-Burke, S., \& Burke, M. D. (2005). The effects of self-regulated strategy development on the writing process for high school students with learning disabilities. Learning Disability Quarterly, 28(1), 75-87. 
Chao, C. L. (1993). The psychological process of writing in college students. Unpublished master's thesis, National Chung Cheng University, Department of Psychology, Chiayi, Taiwan.

Chen, F. R. (2003). A study of the writing process and audiences' awareness of the writers with different abilities. Journal of National Taipei Teachers College, 16(1), 63-88.

Chen, F. Y. (2003). The EFL beginning writers' perception and metacognitive knowledge of English writing-a study on the freshman at a university of science and technology. Unpublished master's thesis. National Yunlin University of Science \& Technology, Department of Applied Language, Yunlin, Taiwan.

Chin, Y. M. (2003). The effect of metacognitive strategy instruction on EFL writing: A case study. Unpublished master's thesis, National Tsing Hua University, Department of Foreign Language \& Literature, Hsinchu, Taiwan.

Cleaveland, M. C., \& Larkins, E. R. (2004). Web-based practice and feedback improve tax students' written communication skills. Journal of Accounting Education, 22, 211-228.

Da La Paz. S., Owenm, B., Harris, K. R., \& Graham, S. (2000). Riding Elvis' motorcycle: Using self-regulated strategy development to PLAN and WRITE for a state writing exam. Learning Disabilities Research Practice, 15(2), 101-109.

Darus, S., Ismail, K., \& Ismail, M. B. M. (2008). Effects of word processing on Arab postgraduate students' essays in EFL. European Journal of Social Sciences, 7(2), 63-77.

El-Hindi, A. E. (1993). Supporting college learners: Metacognition, locus of control, reading composition and writing performance. (ERIC Document Reproduction Service No. 364852).

Flavell, J. H. (1976). Metacognitive aspects of problem solving. In L. B. Resnick (Ed.), The nature of intelligence (pp. 231-235). Hillsdale, NJ: Erlbaum.

Flower, L. S., \& Hayes, J. R. (1980). The dynamics of composing: Making plans and juggling constraints. In L. W. Gregg, \& E. R. Stenberg (Eds.), Cognitive process in writing (pp. 3150). Hillsdale, NJ: Erlbaum.

Flower, L., \& Hayes, J. R. (1981). A cognitive process theory of writing. College Composition and Communication, 32(4), 365-387.

Goddard, Y. L., \& Sendi, C. (2008). Effects of self-monitoring on the narrative and expository writing of four forth-grade students with learning disabilities. Reading \& Writing Quarterly, 24, 408-433.

Graham, S., Harris, K. R. (2005). Writing better: Effective strategies for teaching students with learning difficulties. Baltimore: Paul H. Bookes.

Guo, S. Y. (1998). 教育測驗與評量 [Educational Assessment and Evaluation]. Taipei: Jinghua. Hacker, D. (1998). Definitions and empirical foundations. In D. Hacker, J. Dunlosky, \& A. Graesser (Eds.). Metacognition in educational theory and practice. Mahwah, NJ: Lawrence Erlbaum Associates, Publishers.

Hatch, G. (1991). Reviving the Rodential Model for composition: Robert Zoellner's alternative to Flower and Hayes. (ERIC Document Reproduction Service No. ED 333458).

Hayes, J. R., \& Flower, L. S. (1983). A cognitive model of the writing process in adults. Final report. Washington, D.C: National Inst. of Education. (ERIC Document Reproduction Service No. ED240608).

Huang, G. F. (1985). The productive use of RFL dictionaries. RELC Journal, 16(2), 54-71.

Kasper, L. F. (1997). Assessing the metacognitive groth of ESL student writers. TESL-EJ. Retrieved December 27, 2010, from http://www-writing.berkeley.edu/tesl-ej/ 
ej09/a1.html

Kauffman, D. F., Ge, X., Xie, K., \& Chien, C. H. (2008). Prompting in web-based environments: Supporting self-monitoring and problem solving skills in college students. J. Educational Computing Research, 38(2), 115-137.

Kieft, M., Rijlaarsdam, G., Galbraith, D., \& Bergh, H. (2007). The effects of adapting a writing course to students' writing strategies. British Journal of Educational Psychology, 77, 565-578.

Larios, J. R., Manchón, R., Murphy, L., \& Marín, J. (2008). The foreign language writer's strategic behavior in the allocation of time to writing processes. Journal of Second Language Writing, 17(1), 30-47.

Lee, Y. H., \& You, Y. L. (2005). Exploring EFL Writers' self-regulation during composing process. Selected Papers from the Fourteenth International Symposium on English Teaching (pp. 237-249). Taipei: Crane.

Liao, Y. F. (2005). EFL writers' goal setting during writing: A protocol analysis. Selected Papers from the Fourteenth International Symposium and Book Fair on English Teaching (pp. 405-416). Taipei: Crane.

Lu, I. C., \& Tseng, H. C. (2004). The differences in the metacognitive behaviors during writing process among the sixth graders of different writing abilities. Journal of National Taipei Teachers College, 17(2), 187-212.

Lynch, W. M. (1998). An investigation of writing strategies used by high ability seventh graders responding to a state-mandated explanatory writing assessment task. Draft. Annual Meeting of the American Educational Research Association, 13-17.

MacArthur, C. A., Graham, S., Schwartz, S. S., \& Schafer, W. D. (1995). Evaluation of a writing instruction model that integrated a process approach, strategy instruction, and word processing [Abstract]. Learning Disabilities Quarterly, 18, 278-291.

Maki, O. (2006). Concept mapping as pre-task planning: A case study of three Japanese ESL writers. An International Journal of Educational Technology and Applied Linguistics, 34(4), 566-585.

McCurdy, M., Schmitz, S., \& Albertson, A. (2010). Evidence-based written language instruction: Developing and implementing written language programs at the core, supplemental, and intervention levels. In G. G. Peacock, R. A. Ervin, E. J. Daly III, \& K. W. Merrell (Eds.), Practical handbook of school psychology: Effective practices for the $21^{\text {st }}$ century (pp.300-318). YN: Guilford.

McCutchen, D. (1996). A capacity theory of writing: Working memory in composition. Educational Psychology Review, 8(3), 299-325.

McMillan, J. H., \& Schumacher, S. (2006). Research in education: evidence-based inquiry (6 $6^{\text {th }}$ ed.). Boston, MA: Allyn \& Bacon.

Monahan, B. D. (1984). Revision strategies of basic and competent writers as they write for different audiences [Abstract]. Research in the Teaching of English, 18(3), 227-259.

Moran, M. O., \& Soiferman, I. K. (2010). How an understanding of cognition and metacognition translates into more effective writing instruction. The $11^{\text {th }}$ annual education graduate student symposium (pp.1-33). Manitoba: winnipeg.

Mu, C., \& Carrington, S. (2007). An investigation of three Chinese students' English writing strategies. Teaching English as a Second or Foreign Language, 11(1), 1-23.

Ozagac, O. (2004). Process writing. Bogazici University SFL. Retrieved September 10, 2010, from http://www.buowl.boun.edu.tr/teachers/PROCESS\%20WRITING.htm 
Palinscar, A., \& Brown, A. (1986). Reciprocal teaching of comprehension-fostering and comprehension-monitoring activities. Cognition and instruction, 1, 117-175.

Peacock, M. (2001). Language learning strategies and EAP proficiency: Teacher views, student views and the test result. In J. Flowerdew \& M. Peacock (Eds.), Research Perspectives on English for Academic Purposes. (pp.278-284). Cambridge.

Perin, D., Keselman, A., \& Monopoli, M. (2003). The academic writing of community college remedial students: Text and learner variables. Higher Education, 45(1), 19-42.

Peterson-Karlan, G., Hourcade, J., \& Parette, P. (2008). A review of assistive technology and writing skills for students with physical and educational disabilities. Physical Disabilities: Education and Related Services, 26(2), 13-32.

Raimes, A. (1990). What unskilled ESL students do as they write: A classroom study of composing. TESOL Quarterly, 19, 229-254.

Richards, J. C., \& Renandya, W. A. (2002). Methodology in language teaching. Cambridge: Cambridge University Press.

Sasaki, M. (2000). Toward an empirical model of EFL writing processes: An exploratory study. Journal of Second Language Writing, 9(3), 259-291.

Sasaki, M. (2004). A multiple-data analysis of the 3.5-year development of EFL student writers. Language Learning, 53(3), 525-582.

Scardamalia, M., \& Bereiter, C. (1987). Knowledge telling and knowledge transforming in written composition. In S. Rosenberg (Ed.), Advanced in applied psycholinguistics. NY: University of Cambridge.

Shang, H. F. (2007). An exploratory study of e-mail application on FL writing performance. Computer Assisted Language Learning, 20 (1), 79-96.

Sitko, B. (1998). Knowing how to write: Metacognition and writing instruction. In D. Hacker, J. Dunlosky, \& A. Graesser (Eds.). Metacognition in educational theory and practice. Mahwah, NJ: Lawrence Erlbaum Associates, Publishers.

Stallard, C. K. (1974). An analysis of the writing behavior of good student writers [Abstract]. Research in the Teaching of English, 8, 206-218.

Summit IntelliMetric. (2008). CorrectEnglish. Retrieved December 7, 2010, from http://www.correctenglish.com/personal/

Victori, M. (1999). An analysis of writing knowledge in EFL composing: a case study of two effective and two less effective writers. System, 27, 537-555.

Wang, X. (2004). Encourage self-monitoring in writing by Chinese students. ELT Journal, 58(3), 238-246.

Wu, Y. W. (2007). Writing strategies and writing difficulties among college students of differing English proficiency. Unpublished master's thesis, National Pingtong Institute of Commerce, Department of Applied Foreign Language, Pingtong, Taiwan.

Yagelski, R. P. (1995). The role of classroom context in the revision strategies of student writers [Abstract]. Research in the Teaching of English, 29(2), 216-238.

You, Y. L., \& Joe, S. G. (2000). Composition instruction: A metacognitive approach. The Selected Papers from the Ninth International Symposium on English Teaching (pp. 107117). Taipei: Crane.

You, Y. L., \& Joe, S. G. (2001). Investigating the metacognitive awarneness and strategies of English-majored university student writers. The Selected Papers from the Tenth International Symposium on English Teaching (pp. 106-119). Taipei: Crane. 
You, Y. L., \& Joe, S. G. (2002). Skilled writers' metacognitive conditional knowledge and selfregulation. In the Proceeding of the Nineteenth Conference on English Teaching and Learning in the Republic of China (pp.515-527). Taipei: Crane.

Yu, Y. T. (2006). Effects of automatic essay grading system and bilingual concordance on EFL college students' writing. Unpublished master's thesis, National Tsinghua University of Education, Hsinchu, Taiwan.

Zamel, V. (1983). The composing processes of advanced ESL students: Six case studies. TESOL Quarterly, 17, 165-187.

Zhang, C. X. (2007). 教育心理學 [Educational physiology]. Taipei: Tunghua.

Zhou, L. F. (2006). The story behind English writing: Effects of three metacognitive learning strategy training on EFL senior high school students. Unpublished master's thesis, National Kaohsiung Normal University, Department of English, Kaohsiung, Taiwan. 